\title{
High Incidence of Rickettsiosis Correlated to Prevalence of Rickettsia japonica among Haemaphysalis longicornis Tick
}

\author{
Kenji TABARA $^{1) *}$, Hiroki KAWABATA ${ }^{2}$, Satoru ARAI ${ }^{3)}$, Asao ITAGAKI ${ }^{1)}$, Takeo YAMAUCHI ${ }^{4}$, \\ Takashi KATAYAMA ${ }^{5}$, Hiromi FUJITA ${ }^{6}$ and Nobuhiro TAKADA ${ }^{7)}$ \\ ${ }^{1)}$ Shimane Prefectural Institute of Public Health and Environmental Science, Matsue, Shimane, 690-0122, ${ }^{2)}$ Department of Bacteriology- \\ I, National Institute of Infectious Diseases, Tokyo 162-8640, ${ }^{3)}$ Infection Disease Surveillance Center, National Institute of Infectious \\ Diseases, Tokyo 162-8640, ${ }^{4)}$ Toyama Institute of Health, Imizu, Toyama 939-0363, 5) Kanagawa Prefectural Institute of Public Health, \\ Chigasaki, Kanagawa 253-0087, ${ }^{6}$ Ohara General Hospital, Fukushima, Fukushima 960-0195 and ${ }^{7)}$ University of Fukui, Eiheiji, Fukui \\ 910-1193, Japan
}

(Received 30 August 2010/Accepted 17 November 2010/Published online in J-STAGE 1 December 2010)

ABSTRACT. Endemic spotted fever group rickettsiosis was reported in Shimane Prefecture, Japan. From an analysis of 14 clinical cases found in the endemic area, the infectious agent of spotted fever group rickettsiosis was identified as Rickettsia japonica. In this study, we also found that Rickettsia japonica was highly infected with the vector tick, Haemaphysalis longicornis, in the endemic area. These findings suggest that the high incidence of rickettsiosis in Shimane Prefecture can be explained by the high prevalence of Rickettsia japonica among Haemaphysalis longicornis ticks.

KEY WORDS: ixodid ticks, Japanese deer, Japanese spotted fever, Rickettsia japonica, Shimane Peninsula.

J. Vet. Med. Sci. 73(4): 507-510, 2011

Spotted fever group (SFG) rickettsiosis is known as an important arthropod-borne infectious disease throughout the world. In Japan, Japanese spotted fever (JSF), which is caused by infection of Rickettsia japonica ( $R$. japonica), is known as the tick-borne SFG rickettsiosis. Since the first case of JSF was reported in 1984 [6], 800 or more cases of SFG rickettsiosis have been reported, mainly in the western part of Japan and Pacific coastal areas [8]. In Shimane Prefecture, 110 cases of SFG rickettsiosis were serologically confirmed between 1987 and 2009 [4,9,10,12], of which 102 cases were found in the Misen mountains in the western area of Shimane Peninsula (Fig. 1). However, it is unclear why an endemic focus of SFG rickettsiosis was found in Shimane prefecture.

In order to solve this problem, we attempted to identify the endemic Rickettsia species infecting the cases of SFG rickettsiosis cases reported in a disease accumulation locus. Furthermore, numerous ixodid ticks collected in Shimane Prefecture were provided for genetic study to identify the most competent vector species of the pathogenic Rickettsia.

We obtained 24 specimens from 14 patients confirmed serologically with SFG rickettsiosis as follows: 14 blood specimens ( 6 blood clots and 8 whole blood samples), 8 eschars, and skin samples from one patient with a biting tick. The biting tick was morphologically identified as a female Haemaphysalis longicornis (H. longicornis) tick. These samples were collected in 2008 or 2009 , and all were obtained from patients infected in the Misen mountains.

We extracted DNA using the Generation Capture column Kit (QIAGEN, Germantown, MD, U.S.A.) according to

\footnotetext{
* Correspondence to: Tabara, K., Shimane Prefectural Institute of Public Health and Environmental Science, 582-1 Nishihamasada, Matsue, Shimane 690-0122, Japan. e-mail: tabara-kenji@pref.shimane.lg.jp
}

manufacture's instruction. Blood clot was homogenized in PBS, then $200 \mu l$ of supernatant of homogenized sample was used for DNA extraction. Eschar and skin samples were pretreated with protease before DNA extraction. Whole blood was used directory for DNA extraction.

The Rickettsia 17-kDa genus-common antigen gene and citrate synthesis gene ( $g l t A)$ were amplified using previously published primer pairs, R1 (5' - TCAATTCACAACTTGCCATT-3') and R2 (5'- TTTACAAAATTCTAAAAA CC-3') [1], and RpCS877p (5'- GGGGGCCTGCTCACGGCGG-3') and RpCS1258n (5'- ATTGCAAAAAGTACAGTGAACA-3') [3], respectively. Following PCR amplification, DNA fragments were separated by agarose gel electrophoresis and extracted using the Qiaex Gel Extraction Kit (QIAGEN). DNA sequencing was performed using an ABI PRISM ${ }^{\circledR}$ BigDye ${ }^{\mathrm{TM}}$ Terminator v1.1 Kit (Life Technologies, Carlsbad, CA, U.S.A.) using an ABI Prism 310 Genetic Analyzer (Life Technologies). The nucleotide sequences were compared with the corresponding sequences deposited in GenBank using BLAST (http:// blast.ddbj.nig.ac.jp/top-j.html).

We succeeded in detecting both the Rickettsia $17-\mathrm{kDa}$ genus-common antigen gene and the gltA gene from 4 samples of whole blood, 8 eschars, and both a skin sample with a biting tick and the tick itself (Table 1). All nucleotide sequences of the Rickettsia $17-\mathrm{kDa}$ genus-common antigen gene and the gltA gene were found to be $100 \%$ identical to $R$. japonica (Accession nos. D16515, and DQ909073) and also distinguishable from other Riskettsia species. These results indicate that $R$. japonica is the causative agent of the SFG rickettsiosis in the Misen mountains, suggesting that JSF is endemic in this area.

From 1999 to 2009, we captured 2,099 adult ticks by the flagging method in the Misen mountaines (Area A: ca. 10 


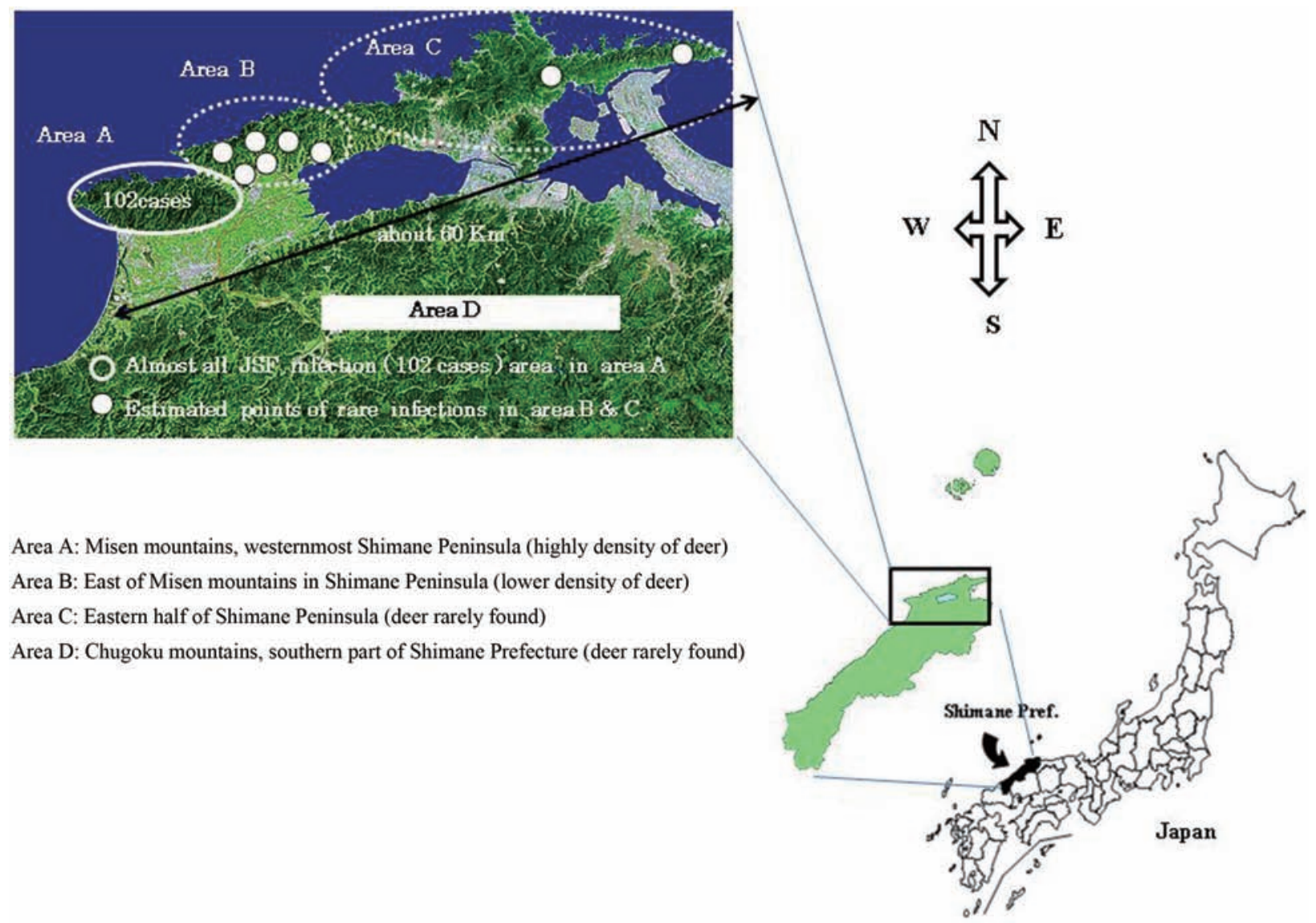

Fig. 1. Distributional pattern of SFG rickettsiosis cases reported in Shimane Prefecture between 1987 and 2009.

$\mathrm{km}$ wide), in the area east of the Misen mountains (Area B: ca.10 km wide neighboring the Misen mountains), in the eastern half of Shimane Peninsula (Area C: ca. $40 \mathrm{~km}$ wide) and in the Chugoku mountains in the southern part of Shimane Prefecture (Area D) (Fig. 1). Ticks were morphologically identified. We also extracted DNA from 2,099 ixodid ticks individually as same as above method, and then used for PCR examination. The prevalence of Rickettsia in ticks was compared across the surveyed area by Fisher's exact test. $P$-values less than 0.05 were considered significant.

Of 2,099 ticks, 1,149 were collected in the Misen mountains (Area A), and 584, 294, and 117 ticks were collected in Area B, C and D, respectively (Fig. 1 and Table 2). These ticks were morphologically identified and were found to include 2 genera and 8 species (Table 2). These collection sizes were mostly associated with the incidence of SFG rickettsiosis cases in the 4 areas, and Area A, as the most endemic area, should be surveyed in detail.

The $R$. japonica DNA was detected from $15 \mathrm{H}$. longicornis $(4.19 \%)$ and 1 Ixodes ovatus (I. ovatus) $(5.26 \%)$ in Area A, and one each of $H$. longicornis $(0.55 \%)$ and I. ovatus $(1.20 \%)$ in Area B (Table 2). The DNA sequences of the ticks were identical to those of $R$. japonica (Accession nos. D16515 and DQ909073) and DNA from clinical specimens.
Statistical analysis revealed that the prevalence of $R$. japonica in ticks collected in Area A was significantly higher than that in Areas B-D (Fisher's exact test of Area A to Areas B$\mathrm{D}: P$-value $=0.0032)$. In particular, the frequency of $R$. japonica was higher among $H$. longicornis than among other ticks in Area A (Fisher's exact test of H. longicornis to sum of others in Area A: $P$-value=2.36e-07) (Table 2). These analyses suggested that $R$. japonica is highly prevalent among the population of $H$. longicornis ticks inhabiting the Misen mountains (Area A) in Shimane Prefecture.

Rickettsia DNA was also detected from I. ovatus collected in Areas A and B. The tick was previously expected as a potential transmission vector of $R$. japonica in Japan. However, it was still unclear whether the tick correlates with disease accumulation in Misen mountains, because of limited number of ticks was collected and examined. To clarify a role of $I$. ovatus in the area, further examination will be required.

It has been reported that SFG reckettsiosis occurs mainly in the Misen mountains situated in the westernmost Shimane Peninsula in Shimane Prefecture [4, 9, 10, 12]. Actually, in Shimane Prefecture, the incidences of JSF cases in Areas A, B, C, and D were 67.4/100,000/year, 4.5/100,000/ year, $0.1 / 100,000 /$ year, and $0 / 100,000 /$ year, respectively. $R$. 
Table 1. Detection of Rickettsia japonica $17-\mathrm{kDa}$ genus-common antigen gene and gltA gene from clinical specimens obtained from 14 rickettsiosis cases

\begin{tabular}{cccccc}
\hline \multirow{2}{*}{ Case No. } & \multicolumn{5}{c}{ Clinical specimens } \\
\cline { 2 - 6 } & Blood clot & Whole blood & Eschar & Skin biopsy & Tick \\
\hline 1 & - & NT & + & NT & NT \\
2 & - & NT & + & NT & NT \\
3 & - & NT & + & NT & NT \\
4 & - & NT & + & NT & NT \\
5 & - & NT & NT & NT & NT \\
6 & - & NT & NT & NT & NT \\
7 & NT & + & NT & NT & NT \\
8 & NT & + & NT & NT & NT \\
9 & NT & + & NT & NT & NT \\
10 & NT & - & + & NT & NT \\
11 & NT & - & + & NT & NT \\
12 & NT & - & + & NT & NT \\
13 & NT & - & + & NT & NT \\
14 & NT & + & NT & $+\$$ & $+\$$ \\
\hline
\end{tabular}

$\$$ : Skin biopsy was performed to erythema lesion. $\dagger$ : Not tested. §: Tick was morphologically identified as a female tick of Haemaphysalis longicornis.

Table 2. Detection of Rickettsia japonica 17-kDa genus-comon antigen gene and gltA gene from ticks

\begin{tabular}{|c|c|c|c|c|c|}
\hline \multirow{3}{*}{ Tick species } & \multicolumn{4}{|c|}{ Area surveyed as shown in Figure } & \multirow{2}{*}{ All areas } \\
\hline & Area $\mathrm{A}$ & Area B & Area $\mathrm{C}$ & Area D & \\
\hline & $\begin{array}{l}\text { No. positive/No. tested } \\
\text { (\% of positive) }\end{array}$ & $\begin{array}{l}\text { No. positive/No. tested } \\
\text { (\% of positive) }\end{array}$ & $\begin{array}{l}\text { No. positive/No. tested } \\
\text { (\% of positive) }\end{array}$ & $\begin{array}{l}\text { No. positive/No. tested } \\
\text { (\% of positive) }\end{array}$ & $\begin{array}{l}\text { No. positive/No. tested } \\
\text { (\% of positive) }\end{array}$ \\
\hline Haemaphysalis flava & 0/97 (0) & $0 / 107(0)$ & $0 / 119(0)$ & $0 / 45(0)$ & $0 / 368(0)$ \\
\hline $\begin{array}{l}\text { Haemaphysalis } \\
\text { longicornis }\end{array}$ & $\begin{array}{c}15 / 358(4.19) \\
P \text { value }=0.0071 \\
\text { (Area A to Areas } \\
\text { B,C\&D)* } \\
P \text { value }=2.36 \mathrm{e}-07 \\
\text { (H. longicornis to sum of } \\
\text { others in Area A)* }\end{array}$ & $1 / 181(0.55)$ & $0 / 15(0)$ & $0 / 31(0)$ & $\begin{array}{c}16 / 585(2.73) \\
P \text { value }=9.6 \mathrm{e}-08 \\
(H . \text { longicornis to } \\
\text { others in all areas)* }\end{array}$ \\
\hline $\begin{array}{l}\text { Haemaphysalis } \\
\text { megaspinosa }\end{array}$ & $0 / 223(0)$ & $0 / 20(0)$ & $0 / 29(0)$ & $\mathrm{NT}^{\dagger}$ & $0 / 272(0)$ \\
\hline $\begin{array}{l}\text { Haemaphysalis } \\
\text { kitaokai }\end{array}$ & $0 / 443(0)$ & $0 / 186(0)$ & $\mathrm{NT}^{\dagger}$ & $\mathrm{NT}^{\dagger}$ & $0 / 629(0)$ \\
\hline $\begin{array}{l}\text { Haemaphysalis } \\
\text { cornigera }\end{array}$ & $0 / 6(0)$ & $0 / 4(0)$ & $\mathrm{NT}^{\dagger}$ & $\mathrm{NT}^{\dagger}$ & $0 / 10(0)$ \\
\hline Ixodes ovatus & $1 / 19(5.26)$ & $1 / 83(1.20)$ & $0 / 73(0)$ & $0 / 40(0)$ & $2 / 215(0.93)$ \\
\hline Ixodes turdus & $0 / 3(0)$ & $0 / 3(0)$ & $0 / 12(0)$ & $\mathrm{NT}^{\dagger}$ & $0 / 18(0)$ \\
\hline Ixodes nipponensis & $\mathrm{NT}^{\dagger}$ & $\mathrm{NT}^{\dagger}$ & $0 / 1(0)$ & $0 / 1(0)$ & $0 / 2(0)$ \\
\hline Total ( $\%$ of positive) & $\begin{array}{l}16 / 1,149(1.39) \\
P \text { value }=0.0032 \\
\text { ea } A \text { to Areas B, C \& D)* }\end{array}$ & $2 / 584(0.34)$ & $0 / 249(0)$ & $0 / 117(0)$ & $18 / 2,099(0.86)$ \\
\hline
\end{tabular}

* Statistical analysis was performed by Fisher's exact test. $\dagger$ PCR was not performed because ticks were not collected in each area.

japonica was more prevalent among $H$. longicornis ticks in Area A than in those in the eastern part of the Misen mountains. H. longicornis is well known as a human-biting tick, and is expected to be a competent vector of $R$. japonica in Japan [7]. These results strongly indicate that the high incidence of JSF cases in the Misen mountains can be explained by the high prevalence of $R$. japonica among $H$. longicornis.
Before this study, three tick species (H. longicornis, Haemaphysalis kitaokai, and Haemaphysalis megaspinosa) with an affinity for Japanese deer (Cervus nippon), were dominant in Area A [13]. The accumulation of deer in Areas A and B was expected, while their population density was reported to be low in Areas C and D [5]. Also, deer inhabiting the Misen mountains are known to have a signif- 
icant antibody against SFG rickettsiae [2]. These findings may suggest that the high prevalence of $R$. japonica among $H$. longicornis ticks is correlated with both the distributional pattern and the population density of the deer. It has been reported that reducing the deer population has decreased the incidence of tick-borne disease by reducing ixodid ticks in the U.S.A. [11]. We considered reductive population control of deer might similarly decrease the JSF incidence in Shimane Prefecture by reducing the numbers of $H$. longicornis from the point of these assessments for public health.

ACKNOWLEDGMENTS. This work was supported in part by a Grant-in-Aid for International Cooperative Research (no. 19406008) from the Japan Society for the Promotion of Science, and also by a Grant-in-Aid for Scientific Research on Emerging and Re-emerging Infectious Diseases from the Japanese Ministry of Health, Labour and Welfare (H21shinkou-ippan-006).

\section{REFERENCES}

1. Furuya, Y., Katayama, T., Yoshida, Y. and Kaiho, I. 1995. Specific amplification of Rickettsia japonica DNA from clinical specimens by PCR. J. Clin. Microbiol. 33: 487-489.

2. Hoshina, K., Itogawa, H., Itagaki, A. and Gomyoda, M. 1995. Serosurvey for spotted fever group rickettsial infection in vertebrates in Shimane Prefecture. J. Jpn. Assoc. Infect. Dis. 69: 524-531 (in Japanese).

3. Ishikura, M., Ando, S., Shinagawa, Y., Matsuura, K., Hasegawa, S., Nakayama, T., Fujita, H. and Watanabe, M. 2003. Phylogenetic analysis of spotted fever group Rickettsiae based on gltA, 17-kDa, and rOmpA genes amplified by nested PCR from ticks in Japan. Microbiol. Immunol. 47: 823-832.

4. Itagaki, A., Matsuda, Y. and Hoshina, K. 2000. Japanese spotted fever in Shimane prefecture-outbreak and place of infection. Jpn. J. Infect. Dis. 53: 73-74.

5. Kanamori, H., Sawada, S., Yamakawa, S., Fujita, Y., Kishimoto, Y. and Katagiri, N. 2009. Monitoring for population dynamics of the Sika deer in the Misen Mountains, Shimane Prefecture, Japan (VII)-Management of population, condition of habitat, population, anatomical examination and forestry damages in 2001-2006. Bull. Shimane Pref. Mt. Reg. Res. Cent. 5: 1-17 (in Japanese).

6. Mahara, F., Koga, K., Sawada, S., Taniguti, T., Sigemi, F., Suto, K., Tsuboi, Y., Oya, A., Koyama, H, Uchiyama, T. and Uchida, T. 1985. The first report of the rickettsial infection of spotted fever group in Japan; three clinical cases. J. Jpn. Assoc. Infect. Dis. 59: 1165-1172 (in Japanese).

7. Mahara, F. 1997. Japanese spotted fever: report of 31 cases and review of the literature. Emerg. Infect. Dis. 3: 105-111.

8. National Institute of Infectious Diseases Control Division, Ministry of Health, Labour and Welfare. 2006. Scrub typhus and Japanese spotted fever in Japan, as of December 2005. Infect. Agents Surveill. Rep. 27: 27-29.

9. Official report by Ministry of Health, Labour and Welfare. Surveillance data table. National Institute of Infectious Diseases in Japan (NIID) [cited 2010 May 10]. Available from http:// idsc.nih.go.jp/idwr/ydata/report-Ea.html, and http:// idsc.nih.go.jp/idwr/ydata/index-e.html]

10. Oka, N., Kato, Y., Dekio, S., Nishio, T., Itagaki, A., Uchiyama, T. and Uchida, T. 1990. A case report of spotted fever group rickettsiosis first encountered in Shimane prefecture. J. Jpn. Assoc. Infect. Dis. 64: 136-141 (in Japanese).

11. Stafford, 3rd K. C. 2007. Tick management handbook. Revised ed. South Windsor: The Connecticut Agricultural Experiment Station; 2007 [cited 2010 May 17]. Available from http:// www.ct.gov/caes/lib/caes/documents/publications/bulletins/ b1010.pdf

12. Tabara, K., Hoshina, K., Itagaki, A., Katayama, T., Fujita, H., Kasosaka, T., Yano, Y., Takada, N. and Kawabata, H. 2006. Epidemiological study of Japanese spotted fever and Tsutsugamushi disease in Shimane Prefecture, Japan. Jpn. J. Infect. Dis. 59: 204-205.

13. Yamauchi, T., Tabara, K., Kanamori, H., Kawabata, H., Arai, S., Katayama, T., Fujita, H., Yano, Y., Takada, N. and Itagaki, A. 2009. Tick fauna associated with sika deer density in the Shimane Peninsula, Honshu, Japan. Med. Entomol. Zool. 60: 297-304. 